\title{
Intervenciones efectivas para reducir el uso innecesario de imágenes en pacientes con dolor lumbar
}

Effective interventions to reduce the unnecessary use of images in patients with low back pain

Jenkins H, y col. CMAJ. 2015;187(6):401-8.

\section{Objetivos}

Evaluar la efectividad de las intervenciones -guías clínicas, auditorias, retroalimentación (en inglés, feedback)- destinadas a disminuir la utilización de métodos diagnósticos innecesarios en pacientes con dolor lumbar.

\section{Diseño, fuente de datos y selección de los estudios}

Revisión sistemática diseñada a partir de las guías del grupo Cochrane para la Práctica y Organización del Cuidado Efectivo (en inglés, EPOC) y la declaración PRISMA. Se realizó la búsqueda bibliográfica de artículos en inglés en MEDLINE, Embase, CINAHL y Registro Cochrane de Estudios Controlados (CENTRAL) hasta junio de 2014. Los estudios elegidos habían evaluado la eficacia de intervenciones para disminuir la utilización de métodos por imágenes en cualquier servicio hospitalario. Fueron incluidos ensayos clínicos aleatorizados, ensayos clínicos controlados y estudios de serie de tiempo interrumpida. El resultado primario fue el número de imágenes realizadas y los secundarios, los resultados en salud y la satisfacción del paciente. La extracción de los datos fue realizada por dos revisores independientes siguiendo la lista de cotejo del Grupo EPOC.

\section{Resultados Principales}

Fueron identificados 8.488 estudios, de los que sólo fueron elegibles siete, cuyos principales hallazgos se resumen en la tabla 1.

Tabla 1. Efectividad de distintas intervenciones destinadas a disminuir el uso de imágenes en pacientes con dolor lumbar evaluadas mediante ensayos clínicos aleatorizados.

\begin{tabular}{|c|c|c|c|c|}
\hline \multirow{2}{*}{$\begin{array}{l}\text { Intervenciones } \\
\text { comparadas }\end{array}$} & \multirow{2}{*}{$\begin{array}{l}\text { Tipo de imágen de columna blanco } \\
\text { de la intervención }\end{array}$} & \multicolumn{2}{|c|}{$\begin{array}{l}\text { Imágenes realizadas cada mil consultas por } \\
\text { rama del estúdio }\end{array}$} & \multirow{2}{*}{$\begin{array}{c}\text { Comparación entre grupos } \\
\text { RR (IC 95\%) }\end{array}$} \\
\hline & & Intervención & Control & \\
\hline Educación médica vs no intervención & \multirow{4}{*}{ Radiografía } & 15,1 & 13,7 & $1,1(0,9$ a 1,4$)$ \\
\hline Auditoria más feedback vs guías de prácticas ${ }^{a}$ & & 6,0 & 6,8 & $0,9(\mathrm{NR})$ \\
\hline Recordatorios ${ }^{\mathrm{b}}$ vs guías de prácticas & & 5,1 & 6,8 & $0,8(\mathrm{NR})$ \\
\hline Educación médica & & 8,3 & 10,2 & $0,8(0,6$ a 1,1$)$ \\
\hline vs guías de prácticas & Tomografía & 6,1 & 6,6 & $0,9(0,7$ a 1,3$)$ \\
\hline
\end{tabular}

a Solo uno de los estudios que había evaluado la eficacia de realizar una auditoría con posterior devolución al médico (feedback) documentó una reducción del $20 \%$. b Los médicos recibieron recordatorios que promovían una racional solicitud de estudios de imágenes luego de cada imagen realizada. RR: riesgos relativos. NR: no reportado.

Las decisiones clínicas con apoyo institucional y los recordatorios a médicos de las indicaciones apropiadas para realizar imágenes en pacientes con lumbalgia redujeron significativamente su utilización un $36,8 \%$ y $22,5 \%$, respectivamente.

\section{Conclusión}

Estas estrategias son potencialmente de bajo costo, y podrían producir una disminución sustancial de los gastos médicos innecesarios en el manejo de los pacientes con lumbalgia.

Fuente de financiamiento/conflicto de interés de los autores: No referida.

\section{Comentario}

En la actualidad existen guías de práctica clínica ${ }^{1}$ que recomiendan restringir la solicitud de estudios de imágenes en pacientes con lumbalgia solo para las personas que presentan alguna manifestación clínica de riesgo (banderas rojas). Estas son: edad mayor de 50 años, antecedentes de neoplasia, algún síndrome con repercusión constitucional sin mejoría con tratamientos habituales, dolor en reposo, fiebre, inmunodepresión, traumatismo previo, osteoporosis, toma de corticoides en forma prolongada, síndrome de la cauda equina y síntomas claros de radiculopatía. En aquellos pacientes que presenten banderas rojas se recomienda la realización de una radiografía de columna, excepto en aquellos que presenten cauda equina o síntomas claros de radiculopatía (pérdida de fuerza y alteración de la sensibilidad en territorio radicular), en quienes estaría indicado realizar una resonancia magnética.
Vale destacar que en la práctica cotidiana, tanto en Argentina como en resto del mundo, existe una sobreutilización de estudios por imágenes en los pacientes con lumbalgia, motivo de consulta extremadamente frecuente en la práctica del médico de atención primaria.

\section{Conclusiones del comentador}

Los autores de la investigación que acabamos de resumir documentaron que la diseminación de guías de prácticas no mostró efectividad para reducir el número de estudios diagnósticos. Sin embargo, las decisiones clínicas con apoyo institucional y los recordatorios lograron reducir el número de imágenes solicitadas a pacientes con lumbalgia.

Gonzalo Eduardo Yamauchi Quintian [ Servicio de Medicina Familiar y Comunitaria. Hospital Italiano de Buenos Aires, gonzalo.yamauchi@ hospitalitaliano.org.ar ]

Yamauchi G. Intervenciones efectivas para reducir el uso innecesario de imágenes en pacientes con dolor lumbar. Evid Act Pract Ambul. 2017:20(3):JulSep-67. Comentado de: Jenkins $\mathbf{H}$ y col. Effectiveness of interventions designed to reduce the use of imaging for low-back pain: a systematic review. CMAJ. 2015 Apr 7;187(6):401-8. doi:10.1503/cmaj.141183. Epub 2015 Mar 2. Review. PMID: 25733741 